\title{
REMOTION Blended Transdiagnostic Intervention for Symptom Reduction and Improvement of Emotion Regulation in an Outpatient Psychotherapeutic Setting: Protocol for a Pilot Randomized Controlled Trial
}

Laura Luisa Bielinski ${ }^{1}, \mathrm{MSc}$; Tobias Krieger ${ }^{1}, \mathrm{PhD}$; Franz Moggi ${ }^{2}, \mathrm{PhD}$; Leonie Trimpop ${ }^{3}$, MSc; Ulrike Willutzki ${ }^{3}$, $\mathrm{PhD}$; Christoph Nissen ${ }^{2}, \mathrm{MD}$; Thomas Berger ${ }^{1}, \mathrm{PhD}$

${ }^{1}$ Department of Clinical Psychology and Psychotherapy, University of Bern, Bern, Switzerland

${ }^{2}$ University Hospital of Psychiatry and Psychotherapy, University of Bern, Bern, Switzerland

${ }^{3}$ Department of Psychology and Psychotherapy, Witten/Herdecke University, Witten, Germany

\section{Corresponding Author:}

Laura Luisa Bielinski, MSc

Department of Clinical Psychology and Psychotherapy

University of Bern

Fabrikstrasse 8

Bern, 3012

Switzerland

Phone: 41316313937

Email: laura.bielinski@psy.unibe.ch

\begin{abstract}
Background: Emotion regulation has been identified as an important transdiagnostic factor relevant to the treatment of mental health disorders. Many empirically validated psychotherapeutic treatments incorporate elements targeting emotion regulation. Most of these treatment approaches are conceptualized as standard face-to-face treatments not as blended treatments, which include an internet-based intervention.

Objective: The aim of this study is to examine, for the first time, a new internet-based intervention—REMOTION—that will be provided transdiagnostically, as an add-on to psychotherapy, to provide a blended treatment format.

Methods: A total of 70 participants will be assigned (1:1 allocation ratio) to either the intervention group (REMOTION + psychotherapy) or the treatment-as-usual group that receives psychotherapy alone. To maximize external validity, a typical outpatient treatment sample of patients diagnosed with a range of disorders such as depression, anxiety disorders, and adjustment disorder will be recruited from a university outpatient clinic. Patients with bipolar disorder, psychotic disorders, or acute suicidality will be excluded from the study. The feasibility and potential effectiveness of the intervention will be examined by assessing data at baseline, 6 weeks (post), and 12 weeks (follow-up). The primary outcome is general symptom severity, assessed with the Brief Symptom Inventory. Secondary outcomes are emotion regulation, depressive symptoms, anxiety symptoms, health related quality of life, well-being, and a variety of feasibility parameters. Quantitative data will be analyzed on an intention-to-treat basis.
\end{abstract}

Results: Participant recruitment and data collection started in February 2020, and as of November 2020, are ongoing. Results for the study are expected in 2022.

Conclusions: This pilot randomized controlled trial will inform future studies using transdiagnostic blended treatment.

Trial Registration: ClinicalTrials.gov NCT04262726; http://clinicaltrials.gov/ct2/show/NCT04262726

International Registered Report Identifier (IRRID): DERR1-10.2196/20936

(JMIR Res Protoc 2020;9(11):e20936) doi: 10.2196/20936

\section{KEYWORDS}

blended therapy; internet-based intervention; emotion regulation; transdiagnostic; online therapy 


\section{Introduction}

\section{Emotion Regulation and Mental Health}

According to Gross [1], emotion regulation refers to "the processes by which individuals influence which emotions they have, when they have them, and how they experience and express these emotions." Emotion regulation can describe how individuals modulate the intensity or duration of an emotion and or the quality of an emotional response; it is often a conscious process, however, can also be an unconscious one [2].

According to several theoretical frameworks, successful emotion regulation is associated with positive health outcomes [3]. In recent years, research has continually shown that emotion regulation is an important transdiagnostic factor relevant to the treatment of mental health disorders [3-5]. Emotion regulation deficits play a role in the development, maintenance, and treatment of a variety of mental health disorders [6]. A number of empirically validated psychotherapeutic treatments incorporate elements of emotion regulation. For example, elements concerning emotion regulation can be found in the Unified Protocol for Transdiagnostic Treatment of Emotional Disorders [7], dialectical behavior therapy [8], accelerated experiential-dynamic psychotherapy [9], and emotion-focused therapy [10].

\section{Treatments Specifically for Emotion Regulation}

Over the past years, there has also been an increase in treatment programs which explicitly target emotion regulation in order to improve mental illness symptoms. Many of these treatments have been carefully developed, and effectiveness has been shown in a number of trials. Examples are acceptance-based emotion regulation group therapy [11]; affect regulation training [12]; emotion regulation therapy [13]; Managing Emotions: Emotions Under Control [14]; Group Therapy for the Improvement of Emotion Regulation Skills [15]; and Gross model-based emotion regulation strategies training on anger reduction [16].

Notably, some of these treatment concepts have also made links to findings from research in basic affective science. Berking and colleagues [17], for example, have integrated findings from affective neuroscience in affect regulation training; they present 7 neural "vicious cycles" important to emotion regulation which are then complemented with 7 skills that are trained in sequence for adaptive emotion regulation. The effects of affect regulation training have been shown in several studies $[17,18]$. Gratz and Gunderson [11] developed emotion regulation group therapy by using a definition that draws on theoretical literature on emotion regulation during childhood and development, and places emphasis on the control of behavior while experiencing an emotion instead of control of the emotion [11]. Emotion regulation group therapy has shown effectiveness in several studies, and mechanisms of change have also been studied $[11,19,20]$. Emotion regulation therapy [21,22] also includes links to affective science by targeting motivational awareness, the development of regulatory capacities, and contextual learning [23] while making reference to theory by Gross [1]. In line with Gross' differentiation of antecedent and response-focused strategies, emotion regulation therapy first teaches individuals adaptive response-focused strategies and then antecedent-focused strategies [24].

\section{The Extended Process Model of Emotion Regulation}

In 2015, Gross presented a valuable extension to the process model of emotion regulation, named the extended process model of emotion regulation [2], elaborating that emotion regulation is an interaction of valuation systems and identifying emotion regulation stages: identification, selection, and implementation. The identification stage is concerned with whether to regulate emotion, the selection stage is concerned with what strategy should be used to regulate emotion, and the implementation stage is concerned with implementing a specific tactic suited to the situation [2]. Furthermore, Gross [2] also mentions the importance of flexibility in emotion regulation, described as matching strategy to circumstance.

A valuable contribution by Gross et al [25] described how elements from the extended process model of emotion regulation pertain to mental illness; maladaptive affect regulation can arise from identification, selection, implementation, and monitoring decisions and individuals can benefit from different treatment aspects and exercises depending on which stage of the model is affected. The intervention in this study, REMOTION, aims to use the stages of emotion regulation of the extended process model of emotion regulation [2] as a general framework for a highly structured transdiagnostic intervention. This intervention aims to foster the use of emotion regulation strategies, while also addressing potential difficulties encountered at each stage of regulation and focuses on training flexibility in emotion regulation strategy use.

\section{Over- and Underregulated Emotional States}

In the field of psychotherapy research, the distinction between over- and underregulated emotional states and its relevance to psychotherapy have been made explicit $[8,10,15,26]$. According to Corcoran and colleagues [27], "one way to classify psychiatric disorders is to consider the degree to which emotions, reported within their syndromal presentation, are over or underregulated." Greenberg [28] states that one guiding factor for integrative psychotherapy interventions may be the type of affect dysregulation involved (too little or too much emotion). Moreover, "whether clients are under- or overregulated and which emotions are to be regulated and how are important issues in any treatment [29]" . In accordance with this view, the same patient can experience both over- and underregulated states, and also exhibit patterns linked more closely to one or the other. Linehan [8,30] developed, in detail, distress tolerance skills relevant to overwhelming underregulated states.

On the other hand, more recently, radically open dialectical behavior therapy was developed for individuals with disorders characterized by overcontrol [26,31,32]. Emotional loneliness is seen as an important problem in disorders characterized by overcontrol [31]. The treatment is aimed at increasing flexible responding, prosocial signaling, openness, and emotional expressiveness of patients while reducing rigid inhibitory control [32]. Within radically open dialectical behavior therapy, specific skills for individuals with overcontrol problems have been 
developed [26]. REMOTION provides explicit strategies for both over- and underregulated states as described by Linehan [8] and Lynch [26], in a blended therapy format.

\section{Internet-Based Interventions}

Over the last decades, the use of internet-based interventions has increased rapidly in the health sector and also in psychotherapeutic treatment. Internet-based interventions have become a popular and effective treatment format for the treatment of a variety of mental health disorders in various countries [33-39]; this has been shown mainly for internet-based cognitive behavioral therapy interventions but also for other treatment contents [40]. Such treatments often allow for more flexibility and convenience in use for the patient [41]. With regard to internet interventions focusing on emotion regulation, González-Robles and colleagues [42] have very recently published a study investigating the effect of an emotion-focused, guided internet treatment in specialized care; the internet intervention was superior to treatment as usual on measures of depression, anxiety, and health-related quality of life.

\section{Blended Treatment}

The combination of internet interventions with conventional face-to-face therapy (blended treatment) is only in its early stages, and studies in a routine care setting are rare. Available studies on blended treatment in routine patient care show positive effects or positive trends for blended treatment [43-47]. For example, a study by Berger and colleagues [34] was able to show that a combination of psychotherapy and internet-based treatment was more effective than psychotherapy alone. Furthermore, Rizvi and colleagues [48], piloted an adjunct treatment for dialectical behavioral therapy called DBT Coach. DBT Coach was given to patients with borderline personality disorder and substance use for 10 to 14 days during outpatient treatment. A decrease of depressive symptoms and general distress was reported [48]. Moreover, Lukas and colleagues [49] piloted a blended therapy emotion regulation approach for individuals with elevated levels of alexithymia that showed positive effects on reducing alexithymia scores.

According to Erbe and colleagues [46], in comparison to purely internet-based treatments or purely face-to-face therapy, blended treatments could offer the following benefits: cost-effectiveness, increased effectiveness of treatment, improved transfer to everyday life, and ability to reach individuals for whom sole face-to-face or internet-based approaches are not suitable. A further benefit of providing interventions in a blended therapy format instead of solely internet-based is the argument that patient emotion regulation is assisted by the therapeutic relationship in session $[10,50]$.

\section{Study Objectives}

This study aims to pilot a blended treatment that uses an internet-based transdiagnostic program to improve emotion regulation (REMOTION) as an add-on to outpatient face-to-face psychotherapy. REMOTION aims to incorporate a variety of elements from effective treatment approaches into the emotion regulation framework provided by Gross [2], while also making explicit to patients specific strategies for over- and underregulated states $[8,10,26]$. The study aims to make use of the benefits of blended therapy format in order to convey emotion regulation skills to patients who are in psychotherapy. REMOTION aims to be a resource for both patient and therapist. This study aims to evaluate the feasibility and first effects of a transdiagnostic, blended treatment focused on emotion regulation in a mixed outpatient sample.

\section{Methods}

\section{Study Design}

The study is a 2-arm pilot randomized controlled trial comparing an intervention group (REMOTION + psychotherapy) with a treatment as usual group (psychotherapy alone). Participants in the intervention group will immediately be given access to REMOTION whereas participants in the treatment as usual group will receive access to REMOTION after 12 weeks. Assessments will occur at baseline, 6 weeks (post), and 12 weeks (follow-up) for all participants. Assessment at 6 and 12 weeks will occur irrespective of whether the patient is still in face-to-face treatment. Figure 1 depicts the design of the trial. The single center trial will take place at the outpatient clinic of the Department of Clinical Psychology and Psychotherapy at the University of Bern, Switzerland. 
Figure 1. Participant flow. TAU: treatment as usual.

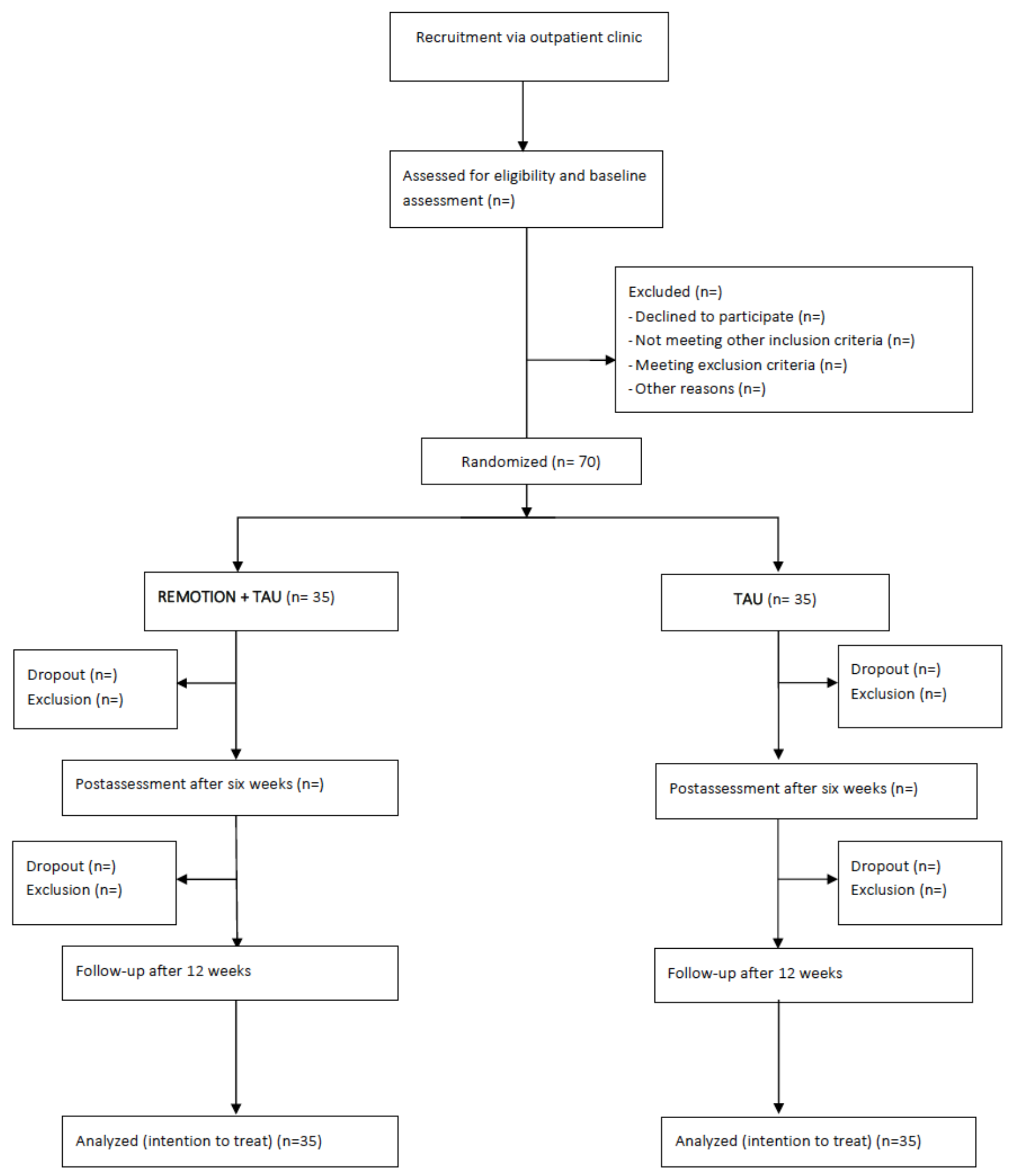

\section{Sample Size}

According to Sim and Lewis [51], 55 participants are the minimum necessary for a pilot trial. Moreover, according to Whitehead and colleagues [52], for a main trial designed with $90 \%$ power and 2 -sided $5 \%$ significance, 25 participants per treatment arm are necessary in the pilot for standardized effect sizes that are small. Furthermore, previous unpublished data at the outpatient clinic for psychotherapy at the University of Bern has shown dropout rates of $15 \%$. Therefore, a final sample size of 70 is planned for the study (35 per trial arm).

\section{Eligibility Criteria}

The inclusion criteria are age over 18 years, in psychotherapeutic treatment, with mental illness, with internet access, and who provide written informed consent. The exclusion criteria are current participation in another intervention specifically for emotion regulation, a current episode or a history of psychotic 
disorders or bipolar disorder, acute suicidality, and not fluent in the German language.

\section{Recruitment, Randomization, and Blinding}

Patients registering at the outpatient clinic will be informed about the study. Interested patients receive an information sheet, are invited to ask questions, and can provide written informed consent if they wish to participate. After study eligibility is proven, participants are randomly assigned to 1 of 2 groups (intervention or treatment as usual). Participants are randomized using a computerized random number generator and randomly permuted block sizes. The allocation schedule is generated by a researcher not involved in the research process and is unknown to the investigators and participants. There is no blinding implemented in the study, consistent with recommendations for the conduct of pragmatic randomized controlled trials in routine practice [53], in which the focus is on external validity and generalizability of the results to routine practice.

\section{Ethical Criteria and Ethics Committee}

The study will be conducted according to local regulations and the Declaration of Helsinki. The study was approved by the ethics committee of the canton of Bern (ID 2019-01929). Written informed consent will be obtained from all patients. The trial is registered with clinicaltrials.gov (NCT04262726).

\section{Intervention}

\section{REMOTION}

REMOTION is an internet-based program that was created at the University of Bern (by LLB in collaboration TB and with input from FM). A more detailed description of the program can be found in Table 1. It is a 6-part program (introduction and 5 modules), and the general sequence and components of the modules are based on the stages of emotion regulation in the extended process model [2]. A variety of elements from different evidence-based psychotherapeutic treatment approaches-dialectical behavior therapy [8], emotion-focused therapy [10], cognitive behavioral therapy [54], mindfulness based cognitive therapy [55], radically open dialectical behavior therapy [26], and Unified Protocol [7]—are incorporated into each module of REMOTION. Furthermore, the focus placed on overregulated as well as underregulated states as described by Greenberg [10] and Lynch [26].

Table 1. REMOTION content.

\begin{tabular}{|c|c|}
\hline Module & Content \\
\hline Introduction & $\begin{array}{l}\text { Information about the structure of the intervention, about the theoretical background, and a user guide are provided in } \\
\text { this module. }\end{array}$ \\
\hline Psychoeducation & $\begin{array}{l}\text { Information is provided about what emotions are, what their functions are, and what types of emotional experiences } \\
\text { there are. The concept of emotion regulation is introduced, and the relationship between emotion regulation and mental } \\
\text { illness is explored. }\end{array}$ \\
\hline Selection & $\begin{array}{l}\text { This module shows patients what types of emotion regulation strategies are available. The focus is on the selection of } \\
\text { an emotion regulation strategy [2]. The strategies_-situation selection or modification, attentional deployment, change } \\
\text { of cognitions, and response modulation [1]_-are introduced in this module. Furthermore, strategies specific to over- } \\
\text { and underregulated states }[10,26,30] \text { are also introduced. }\end{array}$ \\
\hline Monitoring/flexibility & $\begin{array}{l}\text { Being able to modify strategies, being able to apply them flexibly, maintaining, switching, and stopping [2,25] are } \\
\text { discussed in this module. Patients are encouraged to flexibly use strategies, to apply them to different contexts, to } \\
\text { practice, and to try sequences or blends of strategies that work for them as individuals. }\end{array}$ \\
\hline
\end{tabular}

The program is provided to study participants on a platform (hosted by the University of Bern) free of charge and uses text, video, and audio material along with various exercises (Figure 2). Additionally, every week for 6 weeks, individuals in the intervention group receive an email reminding them which module they should be working on. After 9 weeks, patients will receive another email as a reminder to work on the program. Patients will also take part in their routine psychotherapy sessions while using REMOTION. Also, along with the internet-based program given to the patients, the therapists will receive information about the content of REMOTION in the form of an information booklet. The information given to the therapists is meant to explain the content of the internet-based program and provide suggestions as to how elements from the program can be integrated in face-to-face sessions. A detailed description of the information given to the therapist can be found in Table 2. 
Figure 2. REMOTION homepage.

\section{REMOTION}

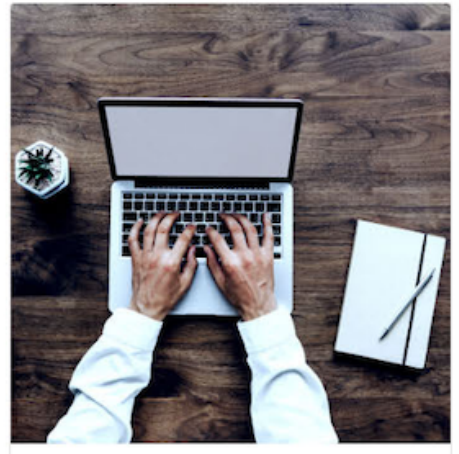

Einführung

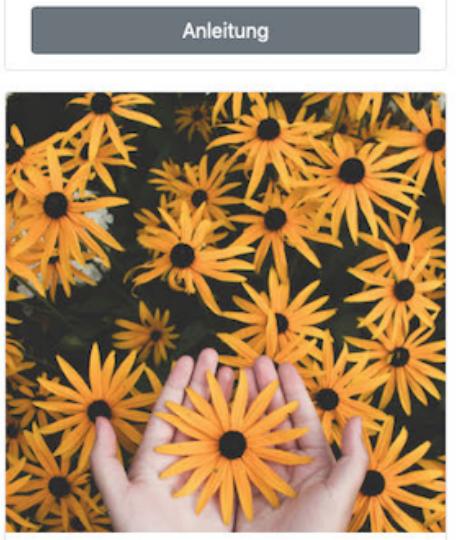

Aussuchen

Modul 3

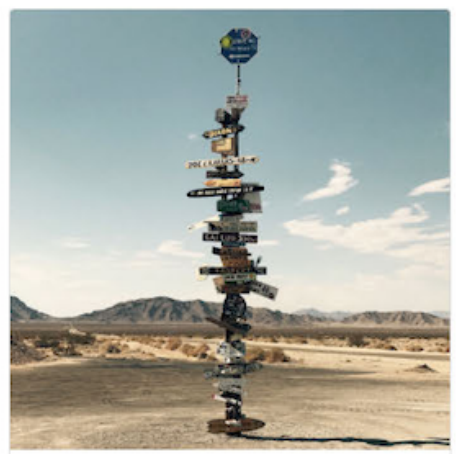

Information
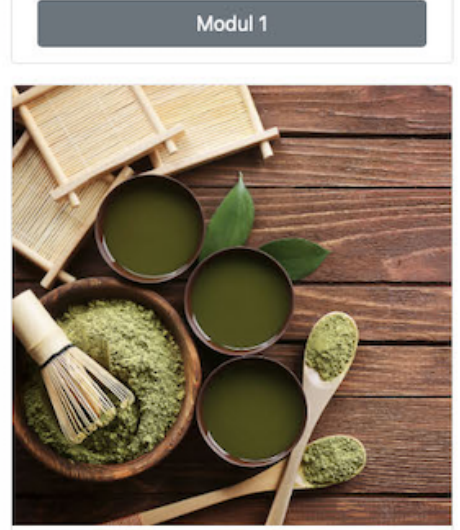

Anwenden

Modul 4

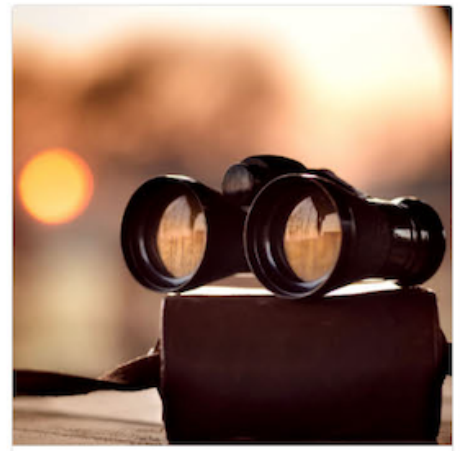

Erkennen

Modul 2

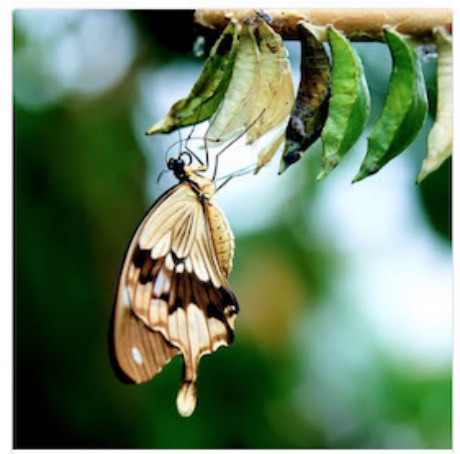

Flexibel Üben

Modul 5

Table 2. Information provided to therapists.

\begin{tabular}{ll}
\hline Chapter & Content \\
\hline $\begin{array}{l}\text { Information about REMOTION } \\
\text { Information about each module }\end{array}$ & $\begin{array}{l}\text { Information about the structure of REMOTION and theoretical background is provided for the therapists. } \\
\text { Each module and its content are outlined for the therapists. Therapists are informed about the exercises } \\
\text { that patients complete in each module. }\end{array}$ \\
$\begin{array}{l}\text { Information on using REMOTION exercises } \\
\text { in face-to-face sessions }\end{array}$ & $\begin{array}{l}\text { Therapists are provided with information as to how they can integrate specific exercises that patients } \\
\text { have completed in the program, in their therapy sessions. }\end{array}$ \\
\hline
\end{tabular}

\section{Treatment as Usual}

Treatment as usual, in this study, consists of psychotherapy as administered in routine practice at the outpatient clinic of the Department of Clinical Psychology and Psychotherapy at the University of Bern. Psychotherapy at the outpatient clinic is an integrative form of cognitive behavioral therapy based on psychological therapy principles [56]. Individual case formulations are key in this treatment approach. This integrative form of cognitive behavioral therapy places a focus on empirically validated interventions and on the following general change factors in psychotherapy: clarification, resource activation, problem activation, and problem solving [57]. A further focus is placed on the analysis of problems and potentials for the therapeutic relationship, such as motive-oriented therapy relationship [58], and on plan analysis [59], which analyses the instrumental functions of patient behavior and experience. Patients in the treatment as usual group will not have access to REMOTION during the 12 -week assessment period. Treatment 
sessions at the outpatient clinic usually take place once a week. The exact number of treatment sessions during the 12-week assessment period will be recorded for each patient.

\section{Therapists}

Psychotherapy is administered by licensed psychotherapists who work at the outpatient clinic of the University of Bern and who have completed postgraduate training in psychotherapy at the University of Bern (Master of Advanced Studies in Psychotherapy), or by psychotherapists in said postgraduate training under regular supervision. All psychotherapists have master's degrees in psychology. Psychotherapists in training have been in training for at least half a year and are regularly supervised. Therapists will be allocated to patients according to capacity at the outpatient clinic, a within-therapist design is used in the study.

\section{Measures}

\section{Overview}

Items recording demographic information of patients will be recorded at baseline, post and follow-up. Also, as part of routine practice in the outpatient clinic, patient diagnostic status will be obtained during the study by conducting a Structured Clinical Interview I (German version) for Diagnostic and Statistical Manual of Mental Disorders (Fourth Edition) [60]. Furthermore, a qualitative interview with questions created specifically for the study will be conducted with a share of participants and therapists in the REMOTION group after 6 weeks. The purpose of this interview is to assess both experience and satisfaction with REMOTION, and thereby, should complement information from the questionnaires.

If deemed necessary, data collection will be aided by emails and phone calls in cases of poor data retention. A full description of all outcomes in the study is provided in the next sections. Unless stated otherwise, measures will be provided online.

\section{Primary Outcome Measure}

The primary outcome measure in this study is general symptom severity as measured with the Brief Symptom Inventory (German version) [61]. The Brief Symptom Inventory will be given to patients at baseline, post and follow-up. The Brief Symptom Inventory contains 53 items and is one of the most frequently used questionnaires to measure general symptom severity. A study [62] has shown that it has good psychometric properties, comparable with those of the Symptom Checklist-90-Revised instrument .

\section{Secondary Outcome Measures}

Emotion regulation will be assessed using 2 different instruments: (1) the German version [63] of Difficulties in Emotion Regulation Scale [64], a 36-item self-report questionnaire consisting of 6 subscales assessing difficulties in emotion regulation, and (2) Fragebogen zur standardisierten Selbsteinschätzung emotionaler Kompetenzen (SEK-27, Emotion Competencies Questionnaire) [65], a 27-item self-report instrument that addresses a range of emotion regulation skills, given to all patients in the study at baseline, 6 weeks, and 12 weeks. Moreover, therapists will also be asked to fill out ratings of patient emotion regulation. Good psychometric properties have been shown for the English [64] and German versions [63] of the Difficulties in Emotion Regulation Scale. The SEK-27 shows both good reliability and validity [65].

Depressive symptoms will be assessed with the German version [66] of the 9-item Patient Health Questionnaire, which is one of the most widely used self-report scales to assess depressive symptoms; criterion validity and change sensitivity have been reported [67].

Anxiety symptoms will be assessed with the German version [68] of the 7-item Generalized Anxiety Disorder Scale, a self-report measure that also shows good psychometric properties.

Health-related quality of life will be assessed with the German version [69] of the 12-item Short Form Health Survey, a frequently used, valid, reliable and change sensitive self-report questionnaire [69] used to assess both physical and psychological aspects of health-related quality of life.

Well-being will be assessed with the German version [70] of the World Health Organization Five Well-Being Index, a widely used economic instrument that shows excellent psychometric properties [70].

Feasibility parameters will be assessed in the study at different measurement timepoints: (1) The number of participants consenting to take part in the study and number of participants randomized will be recorded at the beginning of the study. (2) A previous study has shown that adherence may be an important factor in explaining the difference between effects of internet-based cognitive behavioral therapy in open recruitment and routine practice trials [71]; therefore, adherence to the program in this study will be assessed by number of modules completed at 6 weeks and 12 weeks for the REMOTION group, number of pages visited in the program at 6 weeks and 12 weeks for the REMOTION group, and number of exercises completed at 6 weeks and 12 weeks for the REMOTION group. (3) Usability of REMOTION will be assessed with the 10-item System Usability Scale [72] at 6 weeks and 12 weeks in the REMOTION group. (4) User experience of the REMOTION group will be recorded with the meCUE questionnaire [73], a self-report questionnaire that assesses user experience of products with 34 items at 6 and 12 weeks and with a qualitative interview that will be conducted with a share of the participants after the 6 week point, by telephone. (5) Patient attitudes toward online interventions will be assessed with the German version [74] of the Attitudes toward Psychological Online Interventions Questionnaire at baseline, 6 weeks, and 12 weeks for both study groups. (6) Satisfaction with the intervention will be assessed with the Client Satisfaction Questionnaire (in German [75] and adapted for internet interventions) at 6 and 12 weeks in the REMOTION group. Also, satisfaction will be assessed with qualitative interviews conducted with a share of the participants in the REMOTION group by telephone, after the 6-week point.

\section{Other Measures}

Therapeutic alliance measured with the German version [76] of the Working Alliance Inventory-short revised, a 12-item self-report scale that has shown good psychometric properties [76] will be given to all patients at 6 and 12 weeks. Patient 
self-compassion will be assessed with the German version [77] of the Self-Compassion Scale, a 26-item self-report scale that is both reliable and valid and will be given to all patients at baseline, 6 weeks, and 12 weeks. In order to assess negative effects of the intervention, an adapted version of the Inventory to Assess Negative Effects of Psychotherapy [78] for internet intervention will be used. Only 15 out of 21 items will be used; 6 items geared specifically at conventional psychotherapy will be exempt. The questionnaire is a self-report and will be given to REMOTION group patients at 6 and 12 weeks.

A variety of therapist variables will be recorded in the study, also including demographic data (experience, background, etc) and individual items on general use of emotion regulation interventions in therapy and general use of online interventions in therapy. In the REMOTION group, therapists perceived effect of REMOTION on therapy (attitude toward the intervention, use, satisfaction with the intervention, etc) will also be assessed with a set of items created specifically for the study. An interview will be conducted with a share of the therapists in the REMOTION group after the 6 week timepoint in order to further assess perceived effect of REMOTION on therapy. This interview will also collect data on therapist experience and satisfaction with REMOTION. It will be conducted per telephone.

Patient difficulties in emotion regulation and patient emotion compentencies will be rated by therapists using versions of the Difficulties in Emotion Regulation Scale (original [64], German version [63]) and SEK-27 [65], adapted specifically for this study, at the same measurement timepoints as patients. The wording of the questions is changed as little as possible from the original, but the questions are from an observer's perspective about their patient.

Control of contamination between REMOTION and treatment as usual due to within-therapist design will be controlled in the following ways: the number of therapists who provide both REMOTION and treatment as usual therapies will be recorded, therapists who provide both conditions will be asked explicitly not to talk about REMOTION or use the REMOTION exercises provided in the REMOTION therapist booklet during treatment as usual therapy (a strategy utilized by studies in a review by Magill and colleagues [79]). Adherence to this condition will be recorded with items at post and follow-up for the therapists.

\section{Planned Analysis}

Data will be analyzed on an intention-to-treat basis, meaning that all randomized patients will be included in the outcome analyses and missing data be handled accordingly. The primary outcome measure, general symptom severity, will initially be analyzed descriptively. Within- and between-group effect sizes will be calculated, and linear mixed models will be calculated. These models use all available data on a participant and estimate parameters of missing values. The various secondary outcomes will also be analyzed descriptively, then analyzed with linear mixed models, where applicable. With regard to feasibility parameters, the data will be characterized by descriptive statistics (means, standard deviations, and confidence intervals) in order to allow for comparison with other studies in the field. For categorical data, amount or percentage will be reported.
The qualitative interviews generated for this study, will be analyzed using qualitative content analysis as recommended by Mayring [80]. Results will be reported in accordance with CONSORT (Consolidated Standards of Reporting Trials) [81] and CONSORT-EHEALTH [82].

\section{Results}

The study was approved by the regional ethics committee in January 2020 and was registered with clinicaltrials.gov in February 2020. Participant recruitment and data collection started in February 2020, and as of November 2020, are ongoing. Results for the study are expected in 2022.

\section{Discussion}

\section{General}

This study aims to evaluate the benefit of adding a new transdiagnostic treatment tool, REMOTION, to outpatient psychotherapy. The study aims to provide a tool to improve emotion regulation transdiagnostically and to make use of the benefits of blended therapy as described, for example, by Erbe and colleagues [46]. More generally speaking, the results of this study could be used to improve transdiagnostic treatments of mental illness for patients and provide valuable information on the provision of blended therapy. Although many studies on internet-based and blended treatments are conducted in Switzerland, corresponding intervention formats are not implemented and available in routine practice. With regard to the concept of emotion regulation, to our knowledge, this is the first time an emotion regulation intervention structurally based on the stages of emotion regulation as specified in the extended process model of emotion regulation [2] is used with a clinical population in a blended psychotherapy setting. The application of a basic theoretical concept to a clinical psychotherapy context is a further strength of the study.

\section{Limitations}

The following limitations of the study need to be considered. First, as this is a pilot trial, the number of patients examined in the study is small and thus only preliminary results on the effects of the treatment can be provided. However, this pilot trial can inform future larger studies that would be necessary to examine the efficacy or effectiveness in the future. Also, as this is a pilot study, no conclusions on specificity or mechanisms of change can be made. Moreover, most of the outcomes assessed in the study will be measured via self-report. In emotion regulation literature, the fact that self-report may be limiting has been described [64]. We have, as a result, tried to also include an observer rated assessment of emotion regulation by the therapist. Also, it should be considered, that unlike therapists for treatment as usual, therapists in the intervention group are encouraged to integrate elements of the REMOTION program into their psychotherapy sessions therapy. This may also lead to differences between the 2 study groups. Furthermore, it currently remains unclear what impact the COVID-19 pandemic may have on patient recruitment and data collection. 


\section{Conclusions}

REMOTION is a pilot randomized controlled study, assessing for the first time the feasibility and potential effectiveness of an internet-based emotion regulation treatment (REMOTION) as an add-on to psychotherapy in the form of a blended treatment. The study aims to make emotion regulation tools accessible to a broad range of patients and will provide insight into ways to improve psychotherapy for patients by the provision of internet-based tools. The strength of the approach lies in the application of the theoretical framework in a psychotherapy context and in the use of the treatment modality (blended).

\section{Acknowledgments}

We would like to thank Dania Spagnuolo and Noé Weigl for their contributions to programming the internet-based version of REMOTION. Funding for the study is provided by the Department of Clinical Psychology and Psychotherapy, University of Bern, Switzerland.

\section{Authors' Contributions}

LLB wrote the initial version of the manuscript. All authors contributed to further drafts of the manuscript. TB is the principal investigator of the study.

\section{Conflicts of Interest}

None declared.

\section{References}

1. Gross JJ. The emerging field of emotion regulation: an integrative review. Review of General Psychology 1998 Sep;2(3):271-299 p 275. [doi: 10.1037/1089-2680.2.3.271]

2. Gross JJ. Emotion regulation: current status and future prospects. Psychological Inquiry 2015 Mar 09;26(1):1-26. [doi: 10.1080/1047840X.2014.940781]

3. Aldao A, Nolen-Hoeksema S, Schweizer S. Emotion-regulation strategies across psychopathology: A meta-analytic review. Clin Psychol Rev 2010 Mar;30(2):217-237. [doi: 10.1016/j.cpr.2009.11.004] [Medline: 20015584]

4. Berking M, Wupperman P, Reichardt A, Pejic T, Dippel A, Znoj H. Emotion-regulation skills as a treatment target in psychotherapy. Behav Res Ther 2008 Nov;46(11):1230-1237. [doi: 10.1016/j.brat.2008.08.005] [Medline: 18835479]

5. Sloan E, Hall K, Moulding R, Bryce S, Mildred H, Staiger PK. Emotion regulation as a transdiagnostic treatment construct across anxiety, depression, substance, eating and borderline personality disorders: A systematic review. Clin Psychol Rev 2017 Nov;57:141-163. [doi: 10.1016/j.cpr.2017.09.002] [Medline: 28941927]

6. Berking M, Wupperman P. Emotion regulation and mental health: recent findings, current challenges, and future directions. Curr Opin Psychiatry 2012 Mar;25(2):128-134. [doi: 10.1097/YCO.0b013e3283503669] [Medline: 22262030]

7. Barlow DH, Allen LB, Choate ML. Toward a unified treatment for emotional disorders. Behavior Therapy 2004;35(2):205-230. [doi: 10.1016/S0005-7894(04)80036-4]

8. Linehan MM. Cognitive-behavioural treatment of borderline personality disorder. New York, NY: Guilford Press; 1993.

9. Fosha D, Yeung D. AEDP exemplifies the seamless integration of emotional transformationdyadic relatedness at work. In: Stricker G, Gold J, editors. A Casebook of Psychotherapy Integration. Washington DC: APA Press; 2006.

10. Greenberg LS. Emotion-Focused Therapy: Coaching Clients to Work Through their Feelings (2nd ed.). Washington, DC: American Psychological Association; 2015.

11. Gratz KL, Gunderson JG. Preliminary data on an acceptance-based emotion regulation group intervention for deliberate self-harm among women with borderline personality disorder. Behav Ther 2006 Mar;37(1):25-35. [doi: 10.1016/j.beth.2005.03.002] [Medline: 16942958]

12. Berking M. Training emotionaler Kompetenzen. Berlin: Springer-Verlag; 2017.

13. Mennin DS, Fresco DM. Emotion Regulation Therapy. In: Gross JJ, editor. Handbook of Emotion Regulation (Second Edition). New York: Guilford Press; 2014:469-490.

14. Barnow S, Löw CA, Dodek A, Stopsack M. Gefühle im Griff - Emotionen intelligent regulieren [Managing emotions--emotions under control]. Psychother Psychosom Med Psychol 2014 Jul 20;64(7):284-289. [doi: 10.1055/s-0033-1363683] [Medline: 24446184]

15. Endtner K, Hänni M, Tschacher W. Wirksamkeitsüberprüfung eines gruppenpsychotherapeutischen Verfahrens zur Emotionsregulation. Forschungsberichte der Universitären Psychiatrischen Dienste Bern 2011(11):1.

16. Massah O, Sohrabi F, A'azami Y, Doostian Y, Farhoudian A, Daneshmand R. Effectiveness of Gross model-based emotion regulation strategies training on anger reduction in drug-dependent individuals and its sustainability in follow-up. Int $\mathbf{J}$ High Risk Behav Addict 2016 Mar 20;5(1):e24327 [FREE Full text] [doi: 10.5812/ijhrba.24327] [Medline: 27162759]

17. Berking M, Ebert D, Cuijpers P, Hofmann SG. Emotion regulation skills training enhances the efficacy of inpatient cognitive behavioral therapy for major depressive disorder: a randomized controlled trial. Psychother Psychosom 2013;82(4):234-245. [doi: 10.1159/000348448] [Medline: 23712210] 
18. Berking M, Eichler E, Luhmann M, Diedrich A, Hiller W, Rief W. Affect regulation training reduces symptom severity in depression - A randomized controlled trial. PLoS One 2019 Aug 29;14(8):e0220436 [FREE Full text] [doi: 10.1371/journal.pone.0220436] [Medline: $\underline{31465443}$ ]

19. Gratz KL, Tull MT, Levy R. Randomized controlled trial and uncontrolled 9-month follow-up of an adjunctive emotion regulation group therapy for deliberate self-harm among women with borderline personality disorder. Psychol. Med 2013 Aug 28;44(10):2099-2112. [doi: 10.1017/s0033291713002134]

20. Gratz KL, Bardeen JR, Levy R, Dixon-Gordon KL, Tull MT. Mechanisms of change in an emotion regulation group therapy for deliberate self-harm among women with borderline personality disorder. Behav Res Ther 2015 Feb;65:29-35 [FREE Full text] [doi: 10.1016/j.brat.2014.12.005] [Medline: 25557395]

21. Mennin DS, Fresco DM, Ritter M, Heimberg RG. An open trial of emotion regulation therapy for generalized anxiety disorder and co-occurring depression. Depress Anxiety 2015 Aug 06;32(8):614-623 [FREE Full text] [doi: 10.1002/da.22377] [Medline: 25945946]

22. Mennin DS, Fresco DM, O'Toole MS, Heimberg RG. A randomized controlled trial of emotion regulation therapy for generalized anxiety disorder with and without co-occurring depression. J Consult Clin Psychol 2018 Mar;86(3):268-281 [FREE Full text] [doi: 10.1037/ccp0000289] [Medline: 29504794]

23. Renna ME, Fresco DM, Mennin DS. Emotion regulation therapy and its potential role in the treatment of chronic stress-related pathology across disorders. Chronic Stress 2020 Feb 13;4. [doi: 10.1177/2470547020905787] [Medline: 32440604]

24. Mennin DS, Fresco DM. Emotion regulation as an integrative framework for understanding and treating psychopathology. In: Kring AM, Sloan DM, editors. Emotion regulation and psychopathology: A transdiagnostic approach to etiology and treatment. NY: The Guilford Press; 2009:356-379.

25. Gross JJ, Uusberg H, Uusberg A. Mental illness and well-being: an affect regulation perspective. World Psychiatry 2019 Jun;18(2):130-139 [FREE Full text] [doi: 10.1002/wps.20618] [Medline: 31059626]

26. Lynch TR. The Skills Training Manual for Radically Open Dialectical Behavior Therapy: A Clinician's Guide for Treating Disorders of Overcontrol. Oakland CA: New Harbinger Publications; 2018.

27. Corcoran KM, Farb N, Anderson A, Segal ZV. Mindfulness and Emotion Regulation: Outcomes and Possible Mediating Mechanisms. In: Kring AM, Sloan DM, editors. Emotion Regulation and Psychopathology: A Transdiagnostic Approach to Etiology and Treatment. New York, NY: Guilford Press; 2009:339-355.

28. Greenberg LS. Integrating an emotion-focused approach to treatment into psychotherapy integration. Journal of Psychotherapy Integration 2002;12(2):154-189. [doi: 10.1037/1053-0479.12.2.154]

29. Greenberg LS, Pascual-Leone A. Emotion in psychotherapy: a practice-friendly research review. J Clin Psychol 2006 May;62(5):611-630 p 616. [doi: 10.1002/jclp.20252] [Medline: 16523500]

30. Bohus M, Wolf-Arehult M. Interaktives Skillstraining für Borderline-Patienten. 2. korr Auflage. Stuttgart: Schattauer; 2016.

31. Lynch TR, Gray KL, Hempel RJ, Titley M, Chen EY, O’Mahen HA. Radically open-dialectical behavior therapy for adult anorexia nervosa: feasibility and outcomes from an inpatient program. BMC Psychiatry 2013 Nov 7;13(1). [doi:

10.1186/1471-244x-13-293]

32. Lynch TR, Hempel RJ, Dunkley C. Radically open-dialectical behavior therapy for disorders of over-control: signaling matters. Am J Psychother 2015 Apr;69(2):141-162. [doi: 10.1176/appi.psychotherapy.2015.69.2.141] [Medline: 26160620]

33. Andersson G. Internet-Delivered Psychological Treatments. Annu Rev Clin Psychol 2016;12:157-179. [doi: 10.1146/annurev-clinpsy-021815-093006] [Medline: 26652054]

34. Berger T, Krieger T, Sude K, Meyer B, Maercker A. Evaluating an e-mental health program ("deprexis") as adjunctive treatment tool in psychotherapy for depression: Results of a pragmatic randomized controlled trial. J Affect Disord 2018 Feb;227:455-462. [doi: 10.1016/j.jad.2017.11.021] [Medline: 29154168]

35. Hedman E, Ljótsson B, Lindefors N. Cognitive behavior therapy via the Internet: a systematic review of applications, clinical efficacy and cost-effectiveness. Expert Rev Pharmacoecon Outcomes Res 2012 Dec;12(6):745-764. [doi: 10.1586/erp.12.67] [Medline: 23252357]

36. Richards D, Richardson T, Timulak L, McElvaney J. The efficacy of internet-delivered treatment for generalized anxiety disorder: A systematic review and meta-analysis. Internet Interventions 2015 Sep;2(3):272-282. [doi: 10.1016/j.invent.2015.07.003]

37. Cuijpers P, Marks IM, van Straten A, Cavanagh K, Gega L, Andersson G. Computer-aided psychotherapy for anxiety disorders: a meta-analytic review. Cogn Behav Ther 2009;38(2):66-82. [doi: 10.1080/16506070802694776] [Medline: 20183688]

38. Mayo-Wilson E, Montgomery P. Media-delivered cognitive behavioural therapy and behavioural therapy (self-help) for anxiety disorders in adults. Cochrane Database Syst Rev 2013 Sep 09;9(9). [doi: 10.1002/14651858.CD005330.pub4] [Medline: 24018460]

39. Cheng SK, Dizon J. Computerised cognitive behavioural therapy for insomnia: a systematic review and meta-analysis. Psychother Psychosom 2012;81(4):206-216. [doi: 10.1159/000335379] [Medline: 22585048]

40. Donker T, Bennett K, Bennett A, Mackinnon A, van SA, Cuijpers P, et al. Internet-delivered interpersonal psychotherapy versus internet-delivered cognitive behavioral therapy for adults with depressive symptoms: randomized controlled noninferiority trial. J Med Internet Res 2013;15(5):e82 [FREE Full text] [doi: 10.2196/jmir.2307] [Medline: 23669884] 
41. Berger T. Internetbasierte Interventionen bei psychischen Störungen. Göttingen: Hogrefe; 2015.

42. González-Robles A, Díaz-García A, García-Palacios A, Roca P, Ramos-Quiroga JA, Botella C. Effectiveness of a Transdiagnostic Guided Internet-Delivered Protocol for Emotional Disorders Versus Treatment as Usual in Specialized Care: Randomized Controlled Trial. J Med Internet Res 2020 Jul 07;22(7):e18220 [FREE Full text] [doi: 10.2196/18220] [Medline: $\underline{\text { 32673226] }}$

43. Wright JH, Wright AS, Albano AM, Basco MR, Goldsmith LJ, Raffield T, et al. Computer-assisted cognitive therapy for depression: maintaining efficacy while reducing therapist time. Am J Psychiatry 2005 Jun;162(6):1158-1164. [doi: 10.1176/appi.ajp.162.6.1158] [Medline: 15930065]

44. Kooistra LC, Ruwaard J, Wiersma JE, van Oppen P, van der Vaart R, van Gemert-Pijnen JEWC, et al. Development and initial evaluation of blended cognitive behavioural treatment for major depression in routine specialized mental health care. Internet Interv 2016 May;4:61-71 [FREE Full text] [doi: 10.1016/j.invent.2016.01.003] [Medline: $\underline{30135791]}$

45. Fitzpatrick M, Nedeljkovic M, Abbott J, Kyrios M, Moulding R. "Blended" therapy: The development and pilot evaluation of an internet-facilitated cognitive behavioral intervention to supplement face-to-face therapy for hoarding disorder. Internet Interv 2018 Jun;12:16-25 [FREE Full text] [doi: 10.1016/j.invent.2018.02.006] [Medline: 30135765]

46. Erbe D, Eichert H, Riper H, Ebert DD. Blending Face-to-Face and Internet-Based Interventions for the Treatment of Mental Disorders in Adults: Systematic Review. J Med Internet Res 2017 Sep 15;19(9):e306 [FREE Full text] [doi:

10.2196/jmir.6588] [Medline: 28916506]

47. Lindhiem O, Bennett CB, Rosen D, Silk J. Mobile technology boosts the effectiveness of psychotherapy and behavioral interventions: a meta-analysis. Behav Modif 2015 Nov;39(6):785-804 [FREE Full text] [doi: 10.1177/0145445515595198] [Medline: 26187164]

48. Rizvi SL, Dimeff LA, Skutch J, Carroll D, Linehan MM. A pilot study of the DBT coach: an interactive mobile phone application for individuals with borderline personality disorder and substance use disorder. Behav Ther 2011 Dec;42(4):589-600. [doi: 10.1016/j.beth.2011.01.003] [Medline: 22035988]

49. Lukas CA, Trevisi Fuentes HT, Berking M. Smartphone-based emotion recognition skills training for alexithymia - A randomized controlled pilot study. Internet Interv 2019 Sep;17 [FREE Full text] [doi: 10.1016/j.invent.2019.100250] [Medline: $\underline{31110950]}$

50. Auszra L, Herrmann IR, Greenberg LS. Emotionsfokussierte Therapie: Ein Praxismanual. Göttingen: Hogrefe Verlag; 2017.

51. Sim J, Lewis M. The size of a pilot study for a clinical trial should be calculated in relation to considerations of precision and efficiency. J Clin Epidemiol 2012 Mar;65(3):301-308. [doi: 10.1016/j.jclinepi.2011.07.011] [Medline: 22169081]

52. Whitehead AL, Julious SA, Cooper CL, Campbell MJ. Estimating the sample size for a pilot randomised trial to minimise the overall trial sample size for the external pilot and main trial for a continuous outcome variable. Stat Methods Med Res 2016 Jun;25(3):1057-1073. [doi: 10.1177/0962280215588241] [Medline: 26092476]

53. Zwarenstein M, Treweek S, Gagnier JJ, Altman DG, Tunis S, Haynes B, CONSORT group, Pragmatic Trials in Healthcare (Practihc) group. Improving the reporting of pragmatic trials: an extension of the CONSORT statement. BMJ $2008 \mathrm{Nov}$ 11;337:a2390 [FREE Full text] [doi: 10.1136/bmj.a2390] [Medline: 19001484]

54. Butler AC, Chapman JE, Forman EM, Beck AT. The empirical status of cognitive-behavioral therapy: a review of meta-analyses. Clin Psychol Rev 2006 Jan;26(1):17-31. [doi: 10.1016/j.cpr.2005.07.003] [Medline: 16199119]

55. Segal ZV, Williams M, Teasdale J. Mindfulness-based Cognitive Therapy for Depression. New York, NY: Guilford Publications; 2018.

56. Grawe K. Psychologische Therapie. Göttingen: Hogrefe Verlag für Psychotherapie; 1998.

57. Grawe K. Neuropsychotherapie. Göttingen: Hogrefe; 2004.

58. Grawe K, Caspar F, Ambühl H. Die Berner Therapievergleichsstudie: Wirkungsvergleich und differentielle Indikation [The Bern therapy comparison study: Comparison of effectiveness and differential indication]. Zeitschrift für klinische Psychologie 1990;19(4):338-361.

59. Caspar F. Beziehungen und Probleme verstehen. Eine Einführung in die psychotherapeutische Plananalyse. Bern: Hans Huber; 2007.

60. Witzchen HU, Zaudig M, Fydrich T. Strukturiertes Klinisches Interview für DSM-IV (SKID). Göttingen: Hogrefe; 1997.

61. Franke GH. BSI. Brief Symptom Inventory - Deutsche Version. Manual. Göttingen: Beltz; 2000.

62. Geisheim C, Hahlweg K, Fiegenbaum W, Frank M, Schröder B, von Witzleben I. Das Brief Symptom Inventory (BSI) als Instrument zur Qualitätssicherung in der Psychotherapie. Diagnostica 2002 Jan;48(1):28-36. [doi: 10.1026//0012-1924.48.1.28]

63. Ehring T, Fischer S, Schnülle J, Bösterling A, Tuschen-Caffier B. Characteristics of emotion regulation in recovered depressed versus never depressed individuals. Personality and Individual Differences 2008 May;44(7):1574-1584. [doi: 10.1016/j.paid.2008.01.013]

64. Gratz KL, Roemer L. Multidimensional Assessment of Emotion Regulation and Dysregulation: Development, Factor Structure, and Initial Validation of the Difficulties in Emotion Regulation Scale. Journal of Psychopathology and Behavioral Assessment 2004 Mar;26(1):41-54. [doi: 10.1023/B:JOBA.0000007455.08539.94] 
65. Berking M, Znoj H. SEK-27 Fragebogen zur standardisierten Selbsteinschätzung emotionaler Kompetenzen [Self-Report Measure for the Assessment of Emotion Regulation Skills]. Elektronisches Testarchiv. Trier: Leibniz-Zentrum für Psychologische; 2011. URL: https://www.psycharchives.org//handle/20.500.12034/400 [accessed 2020-11-06]

66. Löwe B, Spitzer R, Zipfel S, Herzog W. Gesundheitsfragebogen für Patienten (PHQ-D). Manual und Testunterlagen. 2. Auflage. Medizinische Universitätsklinik Heidelberg. Karlsruhe: Pfizer; 2002. URL: https://www.klinikum.uni-heidelberg.de/ fileadmin/Psychosomatische Klinik/download/PHQ Manual1.pdf [accessed 2020-11-06]

67. Löwe B, Kroenke K, Herzog W, Gräfe K. Measuring depression outcome with a brief self-report instrument: sensitivity to change of the Patient Health Questionnaire (PHQ-9). Journal of Affective Disorders 2004 Jul;81(1):61-66. [doi: 10.1016/S0165-0327(03)00198-8] [Medline: 15183601]

68. Löwe B, Decker O, Müller S, Brähler E, Schellberg D, Herzog W, et al. Validation and standardization of the Generalized Anxiety Disorder Screener (GAD-7) in the general population. Med Care 2008 Mar;46(3):266-274. [doi: 10.1097/MLR.0b013e318160d093] [Medline: 18388841]

69. Gandek B, Ware JE, Aaronson NK, Apolone G, Bjorner JB, Brazier JE, et al. Cross-validation of item selection and scoring for the SF-12 Health Survey in nine countries: results from the IQOLA Project. International Quality of Life Assessment. J Clin Epidemiol 1998 Nov;51(11):1171-1178. [doi: 10.1016/s0895-4356(98)00109-7] [Medline: 9817135]

70. Brähler E, Mühlan H, Albani C, Schmidt S. Teststatistische Prüfung und Normierung der deutschen Versionen des EUROHIS-QOL Lebensqualität-Index und des WHO-5 Wohlbefindens-Index. Diagnostica 2007 Apr;53(2):83-96. [doi: 10.1026/0012-1924.53.2.83]

71. Romijn G, Batelaan N, Kok R, Koning J, van Balkom A, Titov N, et al. Internet-delivered cognitive behavioral therapy for anxiety disorders in open community versus clinical service recruitment: meta-analysis. J Med Internet Res 2019 Apr 17;21(4):e11706 [FREE Full text] [doi: 10.2196/11706] [Medline: 30994462]

72. Brooke J. SUS-A quick and dirty usability scale. Usability evaluation in industry (194) 1996;189:4-7. [doi: 10.1201/9781498710411-35]

73. Minge M, Riedel L. meCUE - Ein modularer Fragebogen zur Erfassung des Nutzungserlebens. In: Boll S, Maass S, Malaka R, editors. Mensch und Computer 2013: Interaktive Vielfalt. München: Oldenbourg Verlag; 2013:89-98.

74. Schröder J. [Psychometrische Messung von Einstellungen gegenüber psychologischen Online-Interventionen bei depressiven Personen und Psychotherapeuten [ Psychometrical assessment of attitudes towards psychological online interventions in people with depression and psychotherapists]. Universität Hamburg Dissertations. 2015. URL: https://ediss. sub.uni-hamburg.de/handle/ediss/6428 [accessed 2020-11-06]

75. Schmidt J, Lamprecht F, Wittmann WW. Zufriedenheit mit der stationären Versorgung. Entwicklung eines Fragebogens und erste Validitätsuntersuchungen [Satisfaction with inpatient management. Development of a questionnaire and initial validity studies]. Psychother Psychosom Med Psychol 1989 Jul;39(7):248-255. [Medline: 2762479]

76. Wilmers F, Munder T, Leonhart R, Herzog T, Plassmann R, Barth J, et al. Die deutschsprachige Version des Working Alliance Inventory - short revised (WAI-SR) - Ein schulenübergreifendes, ökonomisches und empirisch validiertes Instrument zur Erfassung der therapeutischen Allianz. Klinische Diagnostik und Evaluation 2008;1(3):343-358.

77. Hupfeld J, Ruffieux N. Validierung einer deutschen Version der Self-Compassion Scale (SCS-D). Zeitschrift für Klinische Psychologie und Psychotherapie 2011 Apr;40(2):115-123. [doi: 10.1026/1616-3443/a000088]

78. Ladwig I, Rief W, Nestoriuc Y. Welche Risiken und Nebenwirkungen hat Psychotherapie? - Entwicklung des Inventars zur Erfassung Negativer Effekte von Psychotherapie (INEP). Verhaltenstherapie 2014 Oct 30;24(4):252-263. [doi: 10.1159/000367928]

79. Magill N, Knight R, McCrone P, Ismail K, Landau S. A scoping review of the problems and solutions associated with contamination in trials of complex interventions in mental health. BMC Med Res Methodol 2019 Jan 07;19(1) [FREE Full text] [doi: 10.1186/s12874-018-0646-z] [Medline: $\underline{\text { 30616508] }}$

80. Mayring P. Qualitative Inhaltsanalyse. Grundlagen und Techniken. 12., überarbeitete. Auflage. Weinheim/Basel: Beltz Verlag; 2015.

81. Schulz KF, Altman DG, Moher D, CONSORT Group. CONSORT 2010 Statement: updated guidelines for reporting parallel group randomised trials. BMC Med 2010 Mar 24;8:18 [FREE Full text] [doi: 10.1186/1741-7015-8-18] [Medline: 20334633]

82. Eysenbach G, CONSORT- E. CONSORT-EHEALTH: improving and standardizing evaluation reports of Web-based and mobile health interventions. J Med Internet Res 2011;13(4):e126 [FREE Full text] [doi: 10.2196/jmir.1923] [Medline: 22209829]

\section{Abbreviations}

SEK-27: Fragebogen zur standardisierten Selbsteinschätzung emotionaler Kompetenzen (Emotion Competencies Questionnaire) 
Edited by G Eysenbach; submitted 02.06.20; peer-reviewed by J Apolinário-Hagen, D Erbe; comments to author 14.07.20; revised version received 10.08.20; accepted 27.10.20; published 12.11.20

Please cite as:

Bielinski LL, Krieger T, Moggi F, Trimpop L, Willutzki U, Nissen C, Berger T

REMOTION Blended Transdiagnostic Intervention for Symptom Reduction and Improvement of Emotion Regulation in an Outpatient Psychotherapeutic Setting: Protocol for a Pilot Randomized Controlled Trial

JMIR Res Protoc 2020;9(11):e20936

URL: http://www.researchprotocols.org/2020/11/e20936/

doi: $\underline{10.2196 / 20936}$

PMID: $\underline{3180026}$

(CLaura Luisa Bielinski, Tobias Krieger, Franz Moggi, Leonie Trimpop, Ulrike Willutzki, Christoph Nissen, Thomas Berger. Originally published in JMIR Research Protocols (http://www.researchprotocols.org), 12.11.2020. This is an open-access article distributed under the terms of the Creative Commons Attribution License (https://creativecommons.org/licenses/by/4.0/), which permits unrestricted use, distribution, and reproduction in any medium, provided the original work, first published in JMIR Research Protocols, is properly cited. The complete bibliographic information, a link to the original publication on http://www.researchprotocols.org, as well as this copyright and license information must be included. 